\title{
Assessing Knowledge, Attitude and Practice of Health Care Providers on Integration of Sexual Reproductive Health and HIV Services in Oyo State, South West, Nigeria
}

\author{
Article by Michael Olabode Tomori \\ Strategic Information Unit, AIDS Prevention Initiative in Nigeria, Nigeria \\ E-mail:mtomori@yahoo.com
}

\begin{abstract}
Integration of sexual reproductive health (SRH) and Human Immunodeficiency Virus (HIV) services is very poor in Nigeria, but it is very important because of its benefit to both the clients and the health care providers. However, successful implementation of integration of SRH and HIV services depends a great deal on adequate awareness, knowledge, positive attitude and best practices of all personnel involved in the system. Respondents from 65 health facilities were selected from 20 Local Government Areas in the three Senatorial Districts in the state. Their knowledge, attitude and practice towards the integration of SRH and HIV services programme were assessed. Findings showed that health care providers are adequately aware and also have average knowledge of the integration system. But there is capacity gap identified among the respondents in the area of training and documenting program activities. Also they generally exhibit positive attitude towards the programme but perform most of their service delivery with poor motivation under fairly comfortable working environment. It is recommended amongst others for the system to be very effective, there should be training and retraining programs for the personnel in the health facilities. This will hopefully enhance their skills thus enabling them perform all core integrated services successfully to clients.
\end{abstract}

Keywords: Assessing; Knowledge; Attitude; Practice; Integration; SRH; HIV; Health Care Providers; Oyo State; Nigeria.

\section{Introduction}

There has been a surge in the recognition among the international aid community that global improvement in the health of the people depends greatly upon adequate awareness, knowledge, positive attitude, good practices and complete understanding of all different aspects of the background upon which public health intervention programmes such as the integration of Sexual Reproductive Health and HIV services are implemented (Chinomnso et al, 2012).

Information of this type is typically gathered through different types of cross-sectional surveys on personnel directly involved in various health programmes implementation. Knowledge, Attitude and Practice (KAP) survey which is also known as Knowledge, Attitude, Behaviour and Practice (KABP) survey is the most popular and widely used survey (Nichter 2008).

The scale-up of HIV care and treatment services in sub-Saharan Africa has been followed by calls to address the wider health care needs of people living with HIV (PLWHIV), including their sexual reproductive health (SRH) needs. Both sexual and reproductive health (SRH) services and HIV programs in sub-Saharan Africa are typically delivered vertically, which means that clients see a different provider for each health service. Yet with over 80 percent of HIV infections sexually transmitted (Nihgov, 2013), addressing reproductive health and HIV together would better serve the needs of clients and health care providers in a more comprehensive, cost effective and efficient manner (Stover, 2006). The integration of HIV and SRH services was proposed as an important means to achieve this task as it has the potential to improve the uptake of either sexual reproductive health services, HIV services or both.

It is very plausible to integrate Sexual Reproductive Health (SRH) and Human Immunodeficiency Virus (HIV) infection services indices in a resource poor setting such as Nigeria (NPC, 2009).

The World Health Organization defined integration as the combination of different kinds of services or operational programmes to ensure maximized collective outcomes (WHO, 2004). Clients requiring 
integrated services requires common needs and resources from the health system, therefore such services can be provided under same roof, by the same health care providers and during same working hours. There are many constraints in the health sector that may hinder the successful implementation of the objectives of SRH/HIV integration and reduced the pace and quality of services delivery. One of these constraints is the poor knowledge, attitude and practice of integration by the health care providers who are very critical to the success of the program as they have key roles to play in achieving the objectives of SRH/HIV integration (Bharat et al, 2007). This study is designed to assess the knowledge, attitude and practice of health care providers on SRH/HIV services integration in Oyo State in SouthWest Nigeria.

\section{Statement of the problem}

The integration of SRH and HIV services is poor in Nigeria but very necessary for the uptake of both services. However, one of the challenges facing the implementation of the integration is traceable to the level of the knowledge, attitude and practice (KAP) of health care providers towards it. The need to ensure functional and effective integration of SRH and HIV services justifies the assessment of the KAP of personnel towards integrated services.

\section{Background of study area}

The study area is Oyo State established in April 1976 from the defunct Western States of Nigeria. It is an inland state, lying between latitudes $07^{\circ} 46^{\prime} \mathrm{N}$ and longitudes $03^{\circ} 56^{\prime} \mathrm{E}$, and covers approximately an area of 28,454 square kilometres. There are thirty three (33) Local Government Areas (LGAs) in the state, spread across three Senatorial Districts of Oyo Central, Oyo North and Oyo South, with Ibadan being the capital of the state (Oyostategovng, 2017).

Oyo State has a population of 5,591,589 people (Oyostategovng, 2017). Yoruba is the major language and ethnic tribe; although other Nigerian tribes are resident in the state. The people who reside in the State are of various social, intellectual, religious and cultural affiliations. The major occupations are trading, farming, artisanship, civil servants and private sector workers (Oyostategovng, 2017).This study is set to assess the knowledge, attitude and practice of health care providers on integration of SRH and HIV services in Oyo State. New findings from this research study would form a basis for additional training of health care providers thus enabling them to contribute adequately in the smooth implementation of the integration of SRH and HIV services.

The objectives of this study are:

- To determine the knowledge, attitude and practices of health care providers on integration of SRH and HIV services.

- To determine factors influencing knowledge, attitude and practices of health care providers on integration of SRH and HIV services.

- To come up with recommendations.

\section{Literature review}

In other to collect information for training of personnel and public health intervention programmes planning knowledge, attitude and practice (KAP) surveys are extensively employed. KAP surveys was first used in the field of family planning and population studies in the 1950s. It was then designed to measure the extent to which an obvious hostility to the idea and organization of family planning existed among different populations and to provide information on the knowledge, attitudes and practices on family planning that can be employed for programme justifications globally (Ratcliffe, 1976). However, it was in the 1960s and 1970s that the surveys was used in perceiving and understanding family planning in Africa (Schopper et al, 1993). Knowledge has been identified as a powerful tool for positive change in all aspects of human endeavor including the integration of SRH and HIV services. There are few literatures on KAP studies in Nigeria currently.

A study on KAP of health workers with regards to HIV/AIDS and the prevention of mother to child (PMTCT) transmission of HIV was done in Maiduguri that reveals that the knowledge of the health workers was good. In addition, the Nurses are also considered to have a poor attitude to people living with HIV/AIDS compared to Doctors and Medical Laboratory Scientists (Chama, Yahaya \& Ajayi, 
2007). Recent study by the researcher on the assessment of the knowledge and practice of prevention of mother to child transmission (PMTCT) of HIV documentation among health workers was carried out in Oyo State, the research showed that personnel have good knowledge and practice of documentation of PMTCT program activities (Tomori, 2016). Inadequate training may also undermine the objectives of SRH/HIV integration and reduce the pace and quality of services as the knowledge and skill of the healthcare providers carrying out integration services are affected. Training is an essential component of work schedule of staff as it keeps them abreast and afresh of both existing and new knowledge in their areas of expertise and general health knowledge. It can also be a source of motivation for staff so they could put in more effort (Adebimpe et al, 2013). Building the capacity of health personnel on integrated SRH and HIV services is thus very critical for the successful implementation of integrated services delivery.

\section{Methodology}

\section{Study population}

Those that participated in this study were frontline health care providers working on Sexual Reproductive Health and HIV services in any of the levels of care (primary, secondary or tertiary).

\section{Study design}

This research was a descriptive cross-sectional research design employed to assess the knowledge, attitude and practices of health care providers on integration of SRH and HIV services.

\section{Sample size determination}

The sample size for the cross-sectional part of the quantitative phase of this study was estimated using the formula for calculating sample size for estimating the prevalence of a knowledge, disease or health condition in a population ( $\mathrm{Lu}$ Ann, 2015).

$\mathrm{N}=\left(\mathrm{Z}_{1-\alpha} / \partial\right)^{2} \times \mathrm{p}(1-\mathrm{p})$ Where $\mathrm{N}=$ Minimum sample size, $\mathrm{Z}_{1-\alpha}($ Confidence coefficient $)=1.96$ (corresponding to 2-sided 5\% level of significance), $\partial$ (Width of the interval) $=0.05$

$\mathrm{P}=50 \%$ (Prevalence healthcare providers with good KAP in a population, since prevalence in previous studies was not known 50\% was chosen). Thus, $\mathrm{N}=(1.96 / 0.05)^{2}(0.50 \times 0.50)=384$. However, 414 healthcare providers participated in the study to allow for $10 \%$ non-response.

\section{Inclusion criteria}

All consenting healthcare providers working health facilities carrying out integration of Sexual Reproductive Health and HIV services.

\section{Sampling technique}

A multistage sampling technique was used to select respondents for this study. A sampling frame was generated that was stratified into three levels of care. Simple random balloting was used to select two (2) tertiary hospitals out of the three available through balloting. The secondary facilities were further stratified through random sampling by balloting to select six (6) health facilities across the three senatorial areas. Simple random sampling by balloting was used to select fifty seven (57) primary health facilities in the selected local government areas (LGAs) across the state. In the selected facilities, consecutive sampling was carried out to select participants who met the inclusion criteria.

\section{Instrument for data collection}

A structured, pre-tested, interviewer-administered questionnaire was used to collect the data for the cross-sectional study of the quantitative phase. The questionnaire was developed from review of relevant literatures (articles, journals, websites and books), and inputs from the findings of the interviews conducted in the qualitative phase of this study. The questionnaire was available in English Language only, since all the respondents were educated and could understand English perfectly. 
DOI: $10.21522 /$ TIJPH.2013.05.04.Art035

ISSN: $2520-3134$

\section{Validation of instruments}

To validate the questionnaire, pre-test was done among healthcare providers in facility that was not part of the selected facilities in different location but within the study setting.

\section{Procedure for data collection}

The questionnaire was an interviewer-administered. Prior to administration of questionnaire, verbal informed consent was obtained from each participant following a detailed description of study procedure; privacy of participants and confidentiality of information was ensured during field work.

\section{Data management and data analysis}

All questionnaires were numbered for the purpose of tracking. After each day's data collection, the questionnaires were sorted and kept in a safe place for confidentiality. The obtained data was then entered into the Statistical package for Social Sciences (SPSS) version 21. Data dictionary was developed for questions in the questionnaire, to aid proper analysis. Frequency tables were generated for the various variables. Composite scores were computed for each participant in the different domains; Knowledge, Attitude and Practice. Means of these scores were calculated per domain.

\section{Ethical considerations}

Ethical approval to conduct this study was obtained from the Oyo State Ministry of Health Ethical Research Committee, Ibadan.

\section{Confidentiality of data}

All identifiers which could be linked to particular respondents were not included in data collection. All information collected was securely kept to ensure the safety and privacy of respondents.

\section{Results}

Assessing knowledge attitude and practice of health care provider on SRH/HIV services integration

Table 1. Socio-demographic characteristics of the respondents $(n=414)$

\begin{tabular}{lll}
\hline & Frequency $\mathbf{( n )}$ & Percent $\mathbf{( \% )}$ \\
\hline Type of facility & & \\
Public & 384 & 92.8 \\
Private & 30 & 7.2 \\
Age group & & \\
30 years and below & 114 & 27.5 \\
31-40years & 139 & 33.6 \\
41-50years & 116 & 28.0 \\
51-60years & 45 & 10.9 \\
Sex & & \\
Male & 83 & 20.0 \\
Female & 331 & 80.0 \\
Religion & & \\
Christianity & 306 & 73.9 \\
Islam & 108 & 26.1 \\
Ethnicity & & \\
Yoruba & 400 & 96.6 \\
Igbo & 9 & 2.2 \\
Hausa & 3 & .7 \\
Others & 2 & .5 \\
Designation & & \\
Medical Doctor & 24 & 5.8 \\
Nurse/Midwife & 135 & 32.6
\end{tabular}




\begin{tabular}{lll} 
CHEW & 103 & 24.9 \\
CHO & 44 & 10.6 \\
Record/Data & 33 & 8.0 \\
Officer & 50 & 12.1 \\
Health Assistant & 25 & 6.0 \\
Others & \\
\hline
\end{tabular}

Results from the background characteristics shoes that a larger majority of $92.8 \%$ of the respondents are from public health facilities. The age group with the majority of respondents $(33.6 \%)$ is $31-40$ years. The participants are $80.0 \%$ female mostly Christian Yoruba ethnic group. $32.6 \%$ of the respondents are Nurse/Midwife by designation.

Knowledge of health care providers on integration of Sexual Reproductive Health and HIV services

Table 2. Distribution of items of knowledge of health care providers on integration of sexual reproductive Health and HIV services

\begin{tabular}{|c|c|c|}
\hline Items & Frequency (n) & Percent (\%) \\
\hline \multicolumn{3}{|l|}{$\begin{array}{l}\text { Integration of sexual reproductive health (SRH) } \\
\text { and HIV services means providing both services } \\
\text { under the same facility, at the same time and by } \\
\text { the same health care provider? }\end{array}$} \\
\hline No & 43 & 10.4 \\
\hline Yes & 371 & 89.6 \\
\hline \multicolumn{3}{|l|}{$\begin{array}{l}\text { List the name of family planning methods you } \\
\text { have heard of? }\end{array}$} \\
\hline Pills & 376 & 90.8 \\
\hline IUCD & 375 & 90.6 \\
\hline Injection & 372 & 89.9 \\
\hline Condom & 363 & 87.7 \\
\hline Others (Implant, Vasectomy, etc.,) & 194 & 46.9 \\
\hline \multicolumn{3}{|l|}{$\begin{array}{l}\text { In your understanding, is it suitable for a HIV } \\
\text { positive woman to use different available family } \\
\text { planning methods? }\end{array}$} \\
\hline No & 141 & 34.1 \\
\hline Yes & 273 & 65.9 \\
\hline \multicolumn{3}{|l|}{ If yes, why? } \\
\hline It protects from unintended pregnancy & 231 & 55.8 \\
\hline It protects from sexually transmitted infections & 172 & 41.5 \\
\hline I don’t know & 2 & .4 \\
\hline \multicolumn{3}{|l|}{$\begin{array}{l}\text { In what ways is integration between SRH and } \\
\text { HIV is beneficial? }\end{array}$} \\
\hline $\begin{array}{l}\text { Improved access to and uptake of key HIV and SRH } \\
\text { services }\end{array}$ & 317 & 76.6 \\
\hline Better access of HIV patients to SRH services & 302 & 72.9 \\
\hline Improved coverage of vulnerable population & 255 & 61.6 \\
\hline Greater support for dual protection & 264 & 63.8 \\
\hline Improved quality of care & 256 & 61.8 \\
\hline Ensure program effectiveness and efficiency & 199 & 48.1 \\
\hline \multicolumn{3}{|l|}{$\begin{array}{l}\text { Have you been trained on how document the } \\
\text { integration SRH and HIV services? }\end{array}$} \\
\hline No & 181 & 43.7 \\
\hline Yes & 233 & 56.3 \\
\hline
\end{tabular}


DOI: $10.21522 /$ TIJPH.2013.05.04.Art035

ISSN: $2520-3134$

Which tools do you use for SRH and HIV

services?

HIV client intake form $\quad 192$

Family planning register $\quad 135 \quad 32.6$

Health facility monthly summary form $\quad 147 \quad 35.5$

What day of the month does your facility submit

their report?

$5^{\text {th }}$ to $7^{\text {th }}$ of subsequent month (Right) $\quad 187$

Other dates $\quad 227 \quad 54.8$

What indicators are being used to capture

integration between SRH and HIV services?

HIV clients receiving SHR services $\quad 113 \quad 50.0$

SRH clients receiving HIV services $\quad 56 \quad 24.8$

Both $\quad 57 \quad 25.2$

$89.6 \%$ of the respondents from the table above understood integration of SRH and HIV services. Most of them are knowledgeable on family planning and are conversant with their importance. Participants recognized the benefits of integration, however only $56.3 \%$ of them have been trained. Their understanding of documentation of integration of SRH and HIV services is weak from the study. $45.2 \%$ of respondents knew the right date for the submission of their monthly report and only $25.2 \%$ rightly picked the indicators needed to capture integrated services.

Table 3. Levels of knowledge of health care providers on integration of sexual reproductive health and HIV services

\begin{tabular}{lll}
\hline Knowledge & Frequency & Percent \\
\hline Low & 98 & 23.7 \\
Average & 222 & 53.6 \\
High & 94 & 22.7 \\
Total & $\mathbf{4 1 4}$ & $\mathbf{1 0 0 . 0}$
\end{tabular}

From the table above respondents have an average level of knowledge (53.6\%).

Attitude of health care providers on integration of Sexual Reproductive Health and HIV services

Table 4. Distribution of items of attitude of health care providers on integration of sexual reproductive health and HIV services

\begin{tabular}{lll}
\hline Items & Frequency (n) & Percent (\%) \\
\hline $\begin{array}{l}\text { In the past few months have you spoken to } \\
\text { anyone about SRH/HIV services } \\
\text { integration? }\end{array}$ & \\
No & & \\
Yes & 63 & 15.2 \\
If yes, who did you speak to? & 351 & 84.8 \\
Health worker & & \\
Clients & 23 & 5.6 \\
Both health workers and clients & 299 & 72.2 \\
$\begin{array}{l}\text { Other } \\
\text { Never spoken }\end{array}$ & 24 & 5.8 \\
$\begin{array}{l}\text { Have you ever discouraged or encouraged } \\
\text { anyone from using integration SRH/HIV? }\end{array}$ & 5 & 1.2 \\
Encouraged & 63 & 15.2 \\
& 351 & \\
\end{tabular}


Discouraged

Neither

Reasons for encouragement:

It is reliable

It is cost effective

It is both reliable and cost effective

Others

Never encouraged anyone
9

54

250

38

$58-13$

5

63
2.2

13.0

60.4

9.2

1.2

15.2

The table above showed that the respondents have good attitude towards integration.

Table 5. Categories of attitude of health care providers on integration of sexual reproductive health and HIV services

\begin{tabular}{lll}
\hline Attitude & Frequency & Percent \\
\hline Negative & 94 & 22.7 \\
Positive & 320 & 77.3 \\
Total & $\mathbf{4 1 4}$ & $\mathbf{1 0 0 . 0}$
\end{tabular}

$77.3 \%$ of participants showed positive attitude towards integration of SRH and HIV services

Practices of health care providers on integration of Sexual Reproductive Health and HIV services

Table 6. Distribution of items on practice of health care providers on integration of sexual reproductive health and HIV services

\begin{tabular}{|c|c|c|}
\hline Items & Frequency (n) & Percent $(\%)$ \\
\hline \multicolumn{3}{|l|}{$\begin{array}{l}\text { Is your facility providing integrated services for } \\
\text { HIV and SRH? }\end{array}$} \\
\hline No & 31 & 7.5 \\
\hline Yes & 383 & 92.5 \\
\hline \multicolumn{3}{|l|}{$\begin{array}{l}\text { How does your facility offer SRH services within } \\
\text { HIV counselling and testing services }\end{array}$} \\
\hline $\begin{array}{l}\text { Located in the same service site within the same } \\
\text { facility }\end{array}$ & 266 & 64.3 \\
\hline $\begin{array}{l}\text { Referred to a different service site within the same } \\
\text { facility }\end{array}$ & 104 & 25.1 \\
\hline Referred to another facility & 44 & 10.6 \\
\hline \multicolumn{3}{|l|}{$\begin{array}{l}\text { When a client is referred to your facility, when } \\
\text { does she access the integration services? }\end{array}$} \\
\hline Always on the same day & 310 & 74.9 \\
\hline Sometimes on the same day & 57 & 13.8 \\
\hline Rarely on the same day & 17 & 4.1 \\
\hline I don't know & 30 & 7.2 \\
\hline \multicolumn{3}{|l|}{$\begin{array}{l}\text { Does the patient pay for SRH and HIV } \\
\text { integrated services in the past } 12 \text { months before } \\
\text { the study? }\end{array}$} \\
\hline Yes & 86 & 20.8 \\
\hline No & 328 & 79.2 \\
\hline \multicolumn{3}{|l|}{$\begin{array}{l}\text { In the past } 12 \text { months, was there ever a time in } \\
\text { your facility when rapid test kits for HIV } \\
\text { counselling and testing were unavailable due to } \\
\text { stock-outs? }\end{array}$} \\
\hline Yes & 98 & 23.7 \\
\hline No & 316 & 76.3 \\
\hline
\end{tabular}


DOI: 10.21522/TIJPH.2013.05.04.Art035

ISSN: 2520-3134

In the past 12 months, was there ever a time in your facility when family planning commodities were unavailable due to stock-outs?

Yes 70

16.9

No 344 83.1

The table above showed that there are best practices by the participants in their delivery of integrated services.

Table 7. Classifications of practices of health care providers on integration of sexual reproductive health and HIV services

\begin{tabular}{lll}
\hline Practices & Frequency & Percent \\
\hline Bad & 146 & 35.3 \\
Good & 268 & 64.7 \\
Total & $\mathbf{4 1 4}$ & $\mathbf{1 0 0 . 0}$
\end{tabular}

The practices of health care providers on integration of SRH and HIV services is good (64.7\%).

Association between Designation and Knowledge, Attitude and Practice

Table 8. Chi-square test showing association between designation and knowledge, attitude and practice of integration

\begin{tabular}{lllllc}
\hline \multicolumn{5}{l}{ KNOWLEDGE } \\
\hline DESIGNATION & Low & Average & High & Chi-Square & P-Value \\
\hline Medical Doctor (\%) & $2(8.3)$ & $18(75.0)$ & $4(16.7)$ & 11.549 & 0.483 \\
Nurse/Midwife (\%) & $31(23.0)$ & $72(53.3)$ & $32(23.7)$ & & \\
CHEW (\%) & $29(28.2)$ & $51(49.5)$ & $23(22.3)$ & & \\
CHO (\%) & $8(18.2)$ & $27(61.4)$ & $9(20.5)$ & & \\
Record/Data Officer (\%) & $6(18.2)$ & $19(57.6)$ & $8(24.2)$ & & \\
Health Assistant (\%) & $17(34.0)$ & $21(42.0)$ & $12(24.0)$ & & \\
Others (\%) & $5(20.0)$ & $14(56.0)$ & $6(24.0)$ & & \\
\hline & ATTITUDE & & & \\
\hline DESIGNATION & Negative & & Positive & Chi-Square & P-Value \\
\hline Medical Doctor (\%) & $11(45.8)$ & & $13(54.2)$ & 21.176 & \\
Nurse/Midwife (\%) & $39(28.9)$ & & $96(71.1)$ & & \\
CHEW (\%) & $14(13.6)$ & & $89(86.4)$ & & \\
CHO (\%) & $7(15.9)$ & & $24(84.1)$ & & \\
Record/Data Officer (\%) & $9(27.3)$ & & $44(88.0)$ & & \\
Health Assistant (\%) & $6(12.0)$ & $8(32.0)$ & & & \\
Others (\%) & & & & \\
\hline
\end{tabular}

\section{PRACTICE}

\begin{tabular}{lllll}
\hline DESIGNATION & Bad & Good & Chi-Square & P-Value \\
\hline Medical Doctor (\%) & $14(58.3)$ & $10(41.7)$ & 13.911 & 0.031 \\
Nurse/Midwife (\%) & $48(35.6)$ & $87(64.4)$ & & \\
CHEW (\%) & $31(30.1)$ & $72(69.9)$ & &
\end{tabular}


$\mathrm{CHO}(\%)$

Record/Data Officer (\%)

Health Assistant (\%)

Others $(\%)$
$11(25.0)$

$10(30.3)$

$18(36.0)$

$14(56.0)$
$33(75.0)$

$11(44.0)$

Results from table 8 above showed that there is no significant association between the designations of respondents and their knowledge on integration of HIV and SRH $\left(X^{2}=11.549 ; p=0.483\right)$. Three quarter of the medical doctors (75\%) only have an average knowledge of integration while only two of them $(8.3 \%)$ have low knowledge. Highest knowledge of integration was observed among the junior cadre health workers like record data officer and health assistant who has $24.2 \%$ and $24.0 \%$ respectively. However, the designation with the highest proportion of health workers with low knowledge of integration are still the health assistants (34.0\%).

Nevertheless, the designation of health workers was found to be associated with their attitude towards integration. Although, majority of respondents indicated a positive attitude about integration in each designation, this varies significantly across designations $\left(X^{2}=21.176 ; p=0.002\right)$. Table 8 also showed that medical doctors has the highest proportion of negative attitude $(45.8 \%)$ followed by Nurses/Midwife and Record/Data officer who has $28.9 \%$ and $27.3 \%$ of negative attitude respectively. On the other hand, the health assistants (88\%), CHEW (86.4\%) and CHO (84.1\%) has the highest proportions of positive attitude towards integration.

Relatively, practice of integration is also observed to be related with the designations of respondents. More than half of the medical doctors (58.3\%) have a bad practice of integration of HIV and SRH followed by the health assistants' and nurses who had 36.)\% and 35.6\% of bad practices respectively. The largest majority of good practice $(75.0 \%)$ was observed among the CHO followed by CHEW $(69.9 \%)$ and Record/Data Officer $(69.7 \%)$ respectively. The association is statistically significant $\left(X^{2}=\right.$ 13.911; $p=0.031$ )

\section{Discussion}

The study was towards assessing the knowledge, attitude and practice of health care workers on sexual reproductive health and HIV services integration through the use of cross-sectional quantitative design. Respondents are mostly female nurse/midwife, Christian Yoruba by tribe and majorly work in the public facilities. The mean age of the respondents involved in this study was 38 years with standard deviation \pm 9.74 .

The study showed that most of the respondents understood integration of SRH and HIV services and also, carried out service delivery to patients. Therefore, they are in accord with the calls for integration services (UNFPA, 2004). Participants reported that integration between SRH and HIV related services is beneficial as it improved coverage of vulnerable population, greater support for dual protection, improved quality of care and ensure program efficiency. This aligned with the findings of World Health Organization (WHO, 2004). There is capacity gap among the respondents as nearly half of them (43.7\%) reported not trained. This was also observed in documentation as the findings from the study highlighted.

However, analysis of this study showed that participants have an average level (53.6\%) of knowledge of integration services. In addition, findings from this study showed that respondents exhibited positive attitude towards integration of SRH and HIV services as they encourage clients, fellow health workers and others to access services because of its reliability and cost effectiveness (Stover, 2006). They also showed best practices towards the delivery of integration services. $79.2 \%$ of participants reported that patients received free of charge SRH and HIV services in their facility and many respondents said there isn't stock out essential.

Findings from the study showed that there is no significant association between the designations of respondents and their knowledge of integration of SRH and HIV services. However, the designation of health workers was found to be associated with their attitude towards integration. Although, majority of respondents indicated a positive attitude about integration, it varies significantly across designations. Furthermore, practice of integration was observed to be relatively related with the designations of 
respondents. The largest majority of good practice was observed among the Community Health Officers. This might be as a result of the numbers of respondents administered with the questionnaire.

\section{Conclusion}

Successful implementation of sexual reproductive health and HIV services integration depends a lot on adequate knowledge, positive attitude and best practices of all health care personnel involved in the system.

Most of the facilities in the state are operating integrated services with most of the respondents from public health facilities. The findings from the study showed that participants have average knowledge of integration of SRH and HIV services. They also have a positive attitude to integrated services as most of them encourage health care workers and clients to participate in the system. This is capable of increasing clients' flow to the health facilities. Most of the respondents have good best practice of integration. However, there is capacity gaps identified among the participants identified. Almost half of them have not been trained and their practice of documentation is weak. They need to be trained on integration of SRH and HIV services and documentation of service delivery activities. Good documentation ensures the generation of quality data from which useful information that opinion leaders can use for making inform judgment and policy on integrated services can be obtained. The study also showed that the logistics management information system is very strong and with the free delivery of integration services to patients, there should be improved clients flow. For a successful implementation of the integration of services in the state, it is very crucial that identified gaps in this study is quickly addressed.

\section{Recommendations}

- There should be regular awareness, information, education and communication programs concerning sexual reproductive health and HIV services integration and its importance to health care workers. This will help them appreciate its importance and thus improve their attitude towards it.

- There should be training and retraining for data collection on integrated services to improve. This will help improve the quality of information available for opinion leaders to make useful judgment that will improve program implementation.

- Integration service is a public health system where collaboration with government, health facilities and implementing partners is very crucial. A close collaboration is essential for the effective implementation of sexual reproductive health and HIV services implementation.

\section{References}

[1]. Adebimpe W. O, Akindele R. A, Asekun-Olarinmoye E. O and Olugbenga-Bello, A. I. (2013). Attitude and motivation factors towards volunteering for HIV/AIDS care work in Southern Nigeria. Int. J. Med. Sci. Public Health, 2(4):824-828.

[2]. Bharat, S, Vaishali, A \& Mahendrab, S. (2007). Meeting the Sexual and Reproductive Health Needs of People Living with HIV: Challenges for Health Care Providers Reprod. Health Matters 15(29):93-112.

[3]. Chama, C. M., Yahaya, J.Y., and Ajayi, B. B. (2007). The Knowledge, Attitudes and Practices of Health Workers in Maiduguri with regards to HIV/AIDS and the Prevention of Mother to Child Transmission (PMTCT) of HIV. Kanem Journal of Medical Sciences; 1(1):5-9.

[4]. Chinomnso, C. N., Chika, N.O., Prosper, O.U., and Ugochukwu, U. O. (2012). Awareness and Knowledge of Disease Surveillance and Notification by health-care workers and Availability of facility Records in Anambra State, Nigeria. Nigerian medical Journal, Vol. 53.

[5]. Lu Ann Aday, PhD. Sample Design: How many will be in the sample. Descriptive Studies? The University of Texas of Texas School of Public Health. Available from: higheredbcs.wiley.com/legacy/college/aday/0787975605/.../lecture15.pp (Accessed 17 ${ }^{\text {th }}$ July 2017).

[6]. National Population Commission (NPC). (2009). Nigeria Demographic and Health Survey 2008. Abuja: National Population Commission (NPC) and ICF Macro.

[7]. Nichter, M. (2008): Global Health: Why cultural perceptions, social representations, and biopolitics matter. University of Arizona Press; Tuscon. 
Texila International Journal of Public Health Volume 5, Issue 4, Dec 2017

[8]. Nihgov. (2013). Nihgov. Retrieved 5 July, 2017, from http://www.nichd.nih.gov/womenshealth/STDHIV.cfm.

[9]. Oyostategovng. (2017). Oyostategovng. Retrieved 20 September, 2017, from https://oyostate.gov.ng/aboutoyo-state/.

[10]. Ratcliffe, J. W. (1976): Analyst biases in KAP surveys: A cross-cultural comparison. Studies in Family Planning Vol.7 (11).

[11]. Schopper, D., S. Doussantousse and Orav, J. (1993): Sexual behaviors relevant to HIV transmission in a rural African population: How much can a KAP survey tell us? Social Science \& Medicine; Vol. 37(3). 27. Smith, H. L. (1993): On the limited.

[12]. Stover, J. (2006).

Http://wwwpolicyprojectcom/abstractcfm/2741\%20in\%20post\%202015_27\%20May_Final\%2019H30pdf.

Retrieved 6 July, 2017, from

http://www.policyproject.com/abstract.cfm/2741\%20in\%20post\%202015_27\%20May_Final\%2019H30.pdf

[13]. Tomori, O. M. (2016). Assessing knowledge and practice of prevention of mother to child transmission of HIV documentation among health workers in Oyo State. Texila International Journal of Public Health, 4:4.

[14]. UNFPA (2004). "The New York call to commitment: Linking HIV/AIDS and sexual reproductive health". UNFPA NEWYORK. Accessed from http://www.unfpa.org/icpd/10/docs/hiv-aids-rh-call-commitment.doc.

[15]. World Health Organization (WHO.) (2004). scaling up HIV/AIDS care: Service delivery and human resources perspectives. World Health Organization, Geneva. Available at: http://www.who.int/hrh/documents/en/HRH_ART_paper.pdf Accessed 18th July 2017. 